\title{
Emergent Epileptiform Activity in Neural Networks with Weak Excitatory Synapses
}

\author{
Wim van Drongelen, Hyong C. Lee, Mark Hereld, Zheyan Chen, Frank P. Elsen, and Rick L. Stevens
}

\begin{abstract}
Brain electrical activity recorded during an epileptic seizure is frequently associated with rhythmic discharges in cortical networks. Current opinion in clinical neurophysiology is that strongly coupled networks and cellular bursting are prerequisites for the generation of epileptiform activity. Contrary to expectations, we found that weakly coupled cortical networks can create synchronized cellular activity and seizurelike bursting. Evaluation of a range of synaptic parameters in a detailed computational model revealed that seizure-like activity occurs when the excitatory synapses are weakened. Guided by this observation, we confirmed experimentally that, in mouse neocortical slices, a pharmacological reduction of excitatory synaptic transmission elicited sudden onset of repetitive network bursting. Our finding provides powerful evidence that onset of seizures can be associated with a reduction in synaptic transmission. These results open a new avenue to explore network synchrony and may ultimately lead to a rational approach to treatment of network pathology in epilepsy.
\end{abstract}

Index Terms - Neural modeling, neocortex, epilepsy

\section{INTRODUCTION}

$\mathrm{B}$ ecause the underlying neural mechanisms of epileptiform activity are poorly understood, seizure treatment in the large population of epilepsy patients can be characterized as a trial-and-error process with a fairly limited success rate [1]. A core question in epilepsy research is how abnormalities of intrinsic neural function and network properties manifest themselves as a seizure. Electroencephalograms (EEGs) recorded from patients with epilepsy frequently show epileptic spikes between seizures and a sustained oscillatory pattern with sudden onset and offset during seizures. More often than not, spikes and seizures in the EEG can easily be recognized by an epileptologist or even detected by automated procedures (see, e.g., [2]). Unfortunately these clear-cut patterns at the level of the EEG have not generated insight into the neural mechanisms that underlie epileptiform activity. Most clinical and experimental physiologists envision a scenario in which

Manuscript received November 30, 2004. This work was supported by a Falk Grant and the US Department of Energy, Contract W-31-109-ENG-38.

Wim van Drongelen is with the Department of Pediatrics and the Computation Institute of the University of Chicago, Chicago IL 60637-1470 USA (phone: 773-834-9049; fax: 773-702-4786; e-mail: wvandron@ peds.bsd.uchicago.edu).

Hyong C. Lee, Frank P. Elsen, and Zheyan Chen are with the Department of Pediatrics, The University of Chicago, Chicago IL 60637-1470 USA.

Mark Hereld and Rick L. Stevens are with the Futures Laboratory, Mathematics \& Computer Science, Argonne National Laboratory, Argonne IL 60439 USA, the Computation Institute, and the Department of Computer Science, The University of Chicago, Chicago IL 60637-1470 USA. strong neuronal excitatory connectivity, weak inhibitory synapses, and cellular bursting may lead to a hyperexcitatory and hypersynchronous epileptiform network state (reviewed in [3]). Accordingly, electrophysiological recordings in animal models and computational modeling studies have tended to focus on experimental paradigms where tissue is stimulated, excitation is elevated, and/or inhibition is reduced (e.g., [4][11]). Thus far the understanding gained by these and related studies has not translated into a rational approach to the treatment of epilepsy, perhaps because the activity patterns described in these studies focus on isolated bursts that seem more representative of interictal spikes than true seizures. Recent experimental models that focus on seizure-like, repetitive bursting showed that the neural activity around the onset of seizure-like activity is not always characterized by hypersynchrony [12]-[15]. These findings suggest that the mechanisms for bursting during seizures and interictal spikes may differ significantly and that, therefore, ongoing research in epilepsy requires a specific emphasis on seizure models.

In this report we focus on neocortical microcircuitry that is frequently affected in pediatric patients with epilepsy. We combine modeling with in vitro electrophysiological experiments to evaluate the relationship between the strength of network connectivity and seizure-like activity patterns generated by neocortical networks. In addition, we determine the role of spontaneously bursting cells in sustaining network oscillations. Our computational model contains multicompartmental representations of the neurons and captures the basics of neocortical structure and connectivity by including excitatory and inhibitory neuronal populations, recurrent excitation, inhibition, disinhibition, feedforward loops, and direct electrical coupling between the inhibitory cell types. We demonstrate that the availability of this level of detail can yield insights that suggest new hypotheses and directions for experimental study. Specifically we show that a reduction in excitatory synaptic transmission strength can be associated with emergent seizure-like behavior in both computational and experimental models of neocortex. A short version of this study, and details of the model without bursting cell types, were described previously [16], [17].

\section{PROCEDURES}

\section{A. Model}

To facilitate multiple parameter searches, the computational model was implemented in the parallel GENESIS code [18]. The model runs on the Jazz computing cluster (Argonne National Laboratory, Argonne, IL), which enabled us to perform $>10$ years of single-processor simulation within a two year period. All data reported here is based on a model 
TABLE I

OVERVIEW OF CELL TYPES, COMPARTMENTS, AND ION CHANNELS IN THE NEOCORTICAL MODEL.

\begin{tabular}{|c|c|c|c|}
\hline \multirow{2}{*}{$\frac{\text { Cell - Compartment }}{\text { S_PYRAMIDAL-soma }}$} & Size $(\mu \mathrm{m})$ & V-Channels & Synapse \\
\hline & $22,16.1$ & $\mathrm{Na}, \mathrm{K}, \mathrm{NaP}$ & $\mathrm{i}$ \\
\hline$-\quad-\quad$ sd1 & 140,2 & - & - \\
\hline sd2 & $190,3.3$ & - & $\mathrm{e}$ \\
\hline bd & $200,2.4$ & - & - \\
\hline is & $15,2.5$ & $\mathrm{Na}, \mathrm{K}$ & $\mathrm{i}$ \\
\hline D_PYRAMIDAL-soma & $22,16.1$ & $\mathrm{Na}, \mathrm{K}$ & $\mathrm{i}$ \\
\hline$-\quad-\quad$ dd1 & 250,2 & - & - \\
\hline dd2 & $400,2.9$ & - & - \\
\hline dd3 & $400,4.4$ & - & $\mathrm{e}$ \\
\hline dd4 & $400,4.7$ & - & - \\
\hline bd & $200,6.3$ & - & - \\
\hline is & $15,2.5$ & $\mathrm{Na}, \mathrm{K}$ & $\mathrm{i}$ \\
\hline BASKET1-3-soma & $5.5-22,4-16.1$ & $\mathrm{Na}, \mathrm{K}$ & $e, i$ \\
\hline$-\quad d$ & $300-900,2$ & - & gj \\
\hline CHANDELIER-soma & $5.5,4$ & $\mathrm{Na}, \mathrm{K}$ & e, i \\
\hline$-d$ & 150,2 & - & gj \\
\hline
\end{tabular}

S_PYRAMIDAL, D_PYRAMIDAL $=$ superficial and deep pyramidal cells; BASKET1-3 $=$ three types of basket cells; CHANDELIER $=$ chandelier cell. sd1-2 = superficial cell's dendrite compartments; dd1-4 = deep cell's dendrite compartments; bd = basal dendrite compartment; is = initial segment; $\mathbf{d}=$ dendritic compartment of inhibitory neurons. The size is indicated as length and diameter of the cylindrical compartments in $\mu \mathrm{m}$. Na, $\mathbf{N a P}=$ fast and persistent voltage-sensitive sodium channels; $\mathbf{K}=$ potassium channels; $\mathbf{e}, \mathbf{i}=$ excitatory and inhibitory synaptic channels; $\mathbf{g j}=$ gap junctions.

containing a total of 656 neurons. The field potential as a measure for the overall electrical activity of the neural network was calculated from the weighted sum of the external neuronal currents [19].

\section{B. Experiments}

Neuronal network behavior generated by the model was compared with field potential recordings in mouse neocortical slices. CD-1 mice ( $n=20$, P18-P30) were deeply anesthetized with ether and decapitated at the $\mathrm{C} 3 / \mathrm{C} 4$ spinal level, and cortex samples were isolated in ice-cold artificial cerebrospinal fluid (ACSF). One hemisphere was then glued onto an agar block and mounted into a vibrating tissue slicer. Coronal slices $(500 \mu \mathrm{m}$ thick) that included somatosensory cortex were cut, transferred into a recording chamber, and submerged under a stream of ACSF (temperature, $30^{\circ} \mathrm{C}$; flow rate $10 \mathrm{ml} / \mathrm{min}$; containing (in $\mathrm{mM}$ ): $118 \mathrm{NaCl}, 3 \mathrm{KCl}, 1.5$ $\mathrm{CaCl} 2,1 \mathrm{MgSO} 4,25 \mathrm{NaHCO} 3,1 \mathrm{NaH} 2 \mathrm{PO} 4$, and $30 \mathrm{D}-$ glucose equilibrated with carbogen $(95 \% \mathrm{O} 2,5 \% \mathrm{CO} 2)$. In order to obtain a baseline of low frequency $(<0.1 \mathrm{~Hz})$ network bursting, the potassium concentration was routinely raised from 3 to $5 \mathrm{mM}$ over $30 \mathrm{~min}$.

In the extracellular recordings we evaluated the effects of cadmium $\left(\mathrm{Cd}^{++}, 20-200 \mu \mathrm{M}\right) \quad(n=5)$ and 6-cyano-7nitroquinoxaline-2,3-dione (CNQX, 1-20 $\mu \mathrm{M}) \quad(n=15)$ on network bursting activity. $\mathrm{Cd}^{++}$attenuates $\mathrm{Ca}^{++}$-mediated processes including synaptic transmission. CNQX is a selective antagonist for the non-NMDA (N-methyl-D-aspartic acid) excitatory receptors, i.e. the AMPA ( $\alpha$-amino-3- hydroxy-5-methylisazole-4-proprionic acid) and kainate receptors.

Extracellular recording electrodes were manufactured from borosilicate glass tubes (Clarke GC 150TF), filled with ACSF. The electrodes were positioned in cortical layer 5/6. Extracellular signals were amplified 10,000 times and filtered between 0.25 and $1.5 \mathrm{kHz}$. This resulted in a trace that represented the multiunit AP activity (top trace, Fig. 4a). In order to facilitate detection of action potential bursts, this trace was rectified and integrated by using an electronic integrator with a time constant of $50 \mathrm{~ms}$ ( $\int$ in Fig. 4). The output of the integrator was used as an index of the activity in the population (network) of neurons. Similar to seizure detection in EEG (Gotman, 1990) where seizures are detected by comparison against background activity, seizure-like network bursting was defined as a set of $>5$ bursts with a frequency $>1$ $\mathrm{Hz}$ that could be distinguished from a $100 \mathrm{~s}$ epoch of preceding background activity with a burst frequency $<0.1$ $\mathrm{Hz}$.

\section{COMPUTATIONAL MODEL}

\section{A. Cell Models}

The circuitry depicted in Fig. 1 was built with multicompartmental neuronal models [16], [17]. The dimension of each cylindrical compartment and channel properties are summarized in Table I. Each compartment was modeled as an electric circuit in which the membrane potential $(V)$, the membrane capacitance $\left(C, 0.01 \mathrm{~F} / \mathrm{m}^{2}\right)$, and the currents of the individual ion species $\left(I_{k}\right)$ were related to the intercompartmental current $\left(I_{i}\right)$ by

$$
C \frac{d V}{d t}+\sum I_{k}=I_{i}
$$

The current $\left(I_{k}\right)$ of the $k^{\text {th }}$ ion species is determined from the conductance across the membrane $\left(G_{k}\right)$ and its equilibrium potential $\left(E_{k}\right)$ by $I_{k}=G_{k}\left(V-E_{k}\right)$. The ion conductances are voltage dependent according to the Hodgkin and Huxley formalism [20]. Gating variables $(x)$ that determine the membrane conductance, satisfy first-order kinetics determined by

$$
\frac{d x}{d t}=\alpha(1-x)-\beta x=\left(x_{\infty}-x\right) / \tau_{x} .
$$

The coefficients $\alpha$ and $\beta$ are voltage-dependent rate constants, $x_{\infty}$ is the steady state value and $\tau_{x}$ is the timeconstant. Fast sodium and potassium channels were included in the initial segment of the pyramidal neurons and the soma of the inhibitory cell types ( $\mathrm{Na}, \mathrm{K}$ in Table I). We used kinetics and voltage dependence for $\alpha$ and $\beta$ identical to those described for the squid axon [20]. This choice was motivated by the similarity between $\mathrm{Na}^{+}$and $\mathrm{K}^{+}$conductances reported by [20] and those reported in simulation studies of cortical neurons, [9], [21], [22]. Persistent sodium (NaP) is included in the soma of the pyramidal cells for the simulations for Figs. 2, 3b, 
(a)

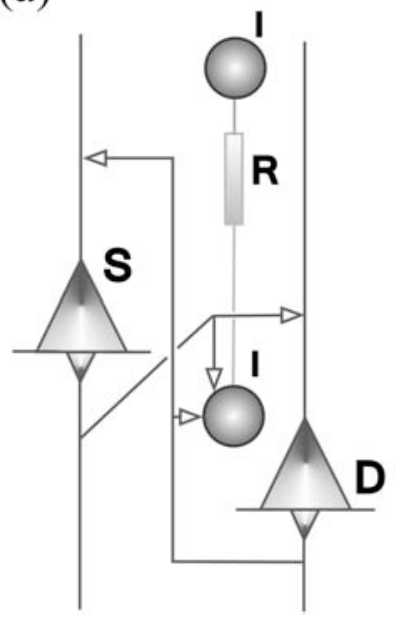

Fig. 1. Cell types and connectivity in the computational model. (a) Excitatory connections and gap junctions between the model elements. (b) Inhibitory connections. Superficial (S) and deep (D) pyramidal cells create a network of recurrent excitation. Inhibitory cell types (I) are connected to the pyramidal cell network and have direct electrical coupling by gap junctions, symbolized by the resistor symbol (R). The inhibitory cell population in the model consists of basket cells (Ba) and chandelier cells (C). These interneurons inhibit the pyramidal neurons creating feedback and feedforward loops. A small percentage of the basket cells inhibit other GABAergic interneurons, providing disinhibition.

and $3 \mathrm{c}$. The conductance for $\mathrm{NaP}$ was calculated as the product of the maximum conductance $\left(100 \mathrm{~S} / \mathrm{m}^{2}\right)$, an activation $(m)$ and inactivation $(h)$ factor. For the activation parameter: $\alpha_{m}=10000 /\{\exp \{-(v-12) / 9\}+1\}$, and $\beta_{m}=$ 10000- $\alpha$. In neocortical pyramidal neurons we observed slow inactivation of the persistent sodium current, therefore we have included an inactivation term $(h)$ following the kinetics described by [23]: $\tau_{h}=1 /(\alpha+\beta)=20 / \cos h\{-(v-5) / 9\}$, and $h_{\infty}=$ $\alpha /(\alpha+\beta)=1.0 /\{\exp \{(v-5) / 9\}+1\}$. The rate variables $\alpha, \beta$ are in $\mathrm{s}^{-1}$ and the time constant $\tau$ is in s. Pyramidal neurons with $\mathrm{NaP}$ channels demonstrated spontaneous bursting activity. This bursting cell model represented the different neocortical bursting populations.

\section{B. Microcircuitry}

The microcircuitry in the computational model is based on the horizontal and vertical organization of the neocortex [24][26]. The cell types and their connectivity within the computational model network are shown in Fig. 1. The excitatory cell population, representing $80 \%$ of the neurons, consists of units representing superficial pyramidal cells concentrated in layers 2, 3 (S; Fig. 1) and deep pyramidal cells in layers 5, 6 (D; Fig. 1). The pyramidal neurons have mutual excitatory connections and are inhibited by smaller interneurons (I; Fig. 1a). This structure forms the basis for the neocortical circuitry that was first proposed in the 1990s, for example [5], [26], [27]. We extended the canonical microcircuitry to include different inhibitory cell types $(\mathrm{Ba}$, basket cells; C, chandelier cells; Fig. 1b) and spontaneously bursting cells [5], [28], [29]. The cell models were arranged in three layers: the superficial pyramidal cells at a depth of 350 $\mu \mathrm{m}$, the interneurons at a depth of $900 \mu \mathrm{m}$, and the deep (a)

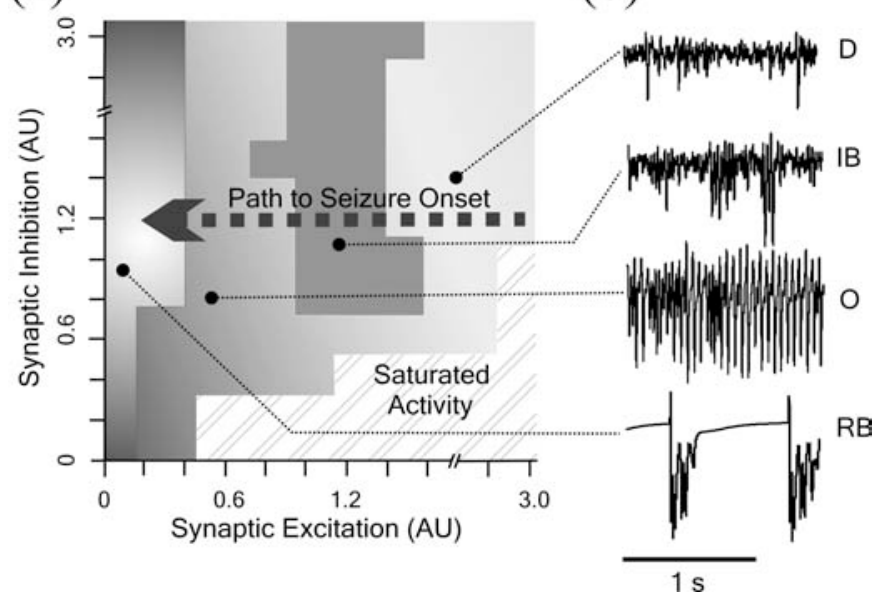

Fig. 2. Impact of variations in excitatory and inhibitory synaptic strengths (in arbitrary units, AU) on the calculated extracellular activity. The domains of activity patterns in the excitation-inhibition parameter space are shown in (a), and representative simulated activity patterns in (b). The arrow indicates the path that was followed to generate the seizure onset activity in Fig. 3. Abbreviations: D-desynchronized activity, IB-irregular bursting, Ooscillatory activity, RB-regular bursting.

pyramidal cells at a depth of $1450 \mu \mathrm{m}$. Interdistances were set to $5 \mu \mathrm{m}$ and $15 \mu \mathrm{m}$ for the pyramidal cells and interneurons respectively.

We included three types of basket cell classified on the basis of their axon arbor spread [28] into local (LAC), medium (MAC), and wide arbor cells (WAC). The maximum probability of pyramidal cells to interconnect was set to $10 \%$ and decreased with distance $(d$ in $\mu \mathrm{m})$ according to $\exp \{-$ $300 d\}$; connectivity between pyramidal cells and interneurons was $25 \%$. In this study we focused on the synchronizing effects of local processes; long-range connections between excitatory neurons (i.e. $>1 \mathrm{~mm}$ ) were not included. The inhibitory interneurons connected to the pyramidal cells with a probability of $0.5 \%, 1 \%, 4 \%$, and $4 \%$ for the WAC, MAC, LAC, and chandelier cell respectively [16], [28]. Probability for the interconnections between the basket cells was $14 \%$ [16], [26], [29].

Conductance in the synapse was simulated with an alpha function for the excitatory synapses and a dual exponential function for the inhibitory connections. In these functions we used values for the time constants described by [30]. Effects of synaptic strength were studied by applying a scale factor to the maximum conductance of the excitatory synaptic contacts (Fig. 1a, e in Table I) and the inhibitory connections (Fig. 1b, $\mathrm{i}$ in Table I) independently.

\section{Emergent Bursting Behavior}

The model network generated a broad variety of behavior that depended critically on the strength of the synaptic connections between neurons as well as the presence of $\mathrm{NaP}$ channels. An overview of the activity patterns is shown in Fig. 2 , in which synaptic strength was varied by applying two independent scale factors to the maximum synaptic conductances: one to the excitatory synapses shown in Fig. 1a, and one to the inhibitory connections depicted in Fig. $1 \mathrm{~b}$. 
(a) Bursting Cells Absent

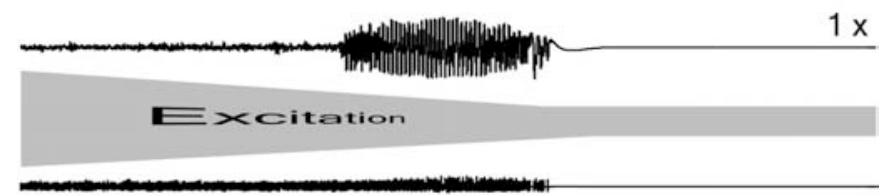

$10 x$

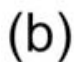

\section{Bursting Cells Included}
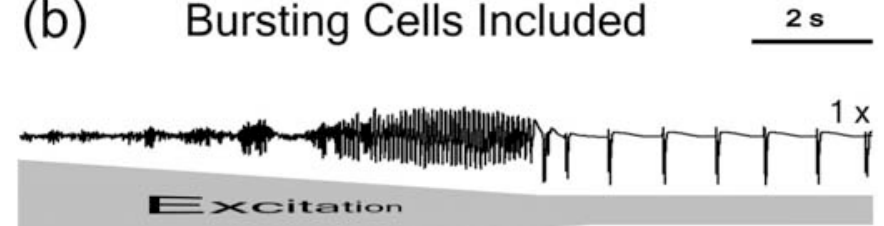

Excitation

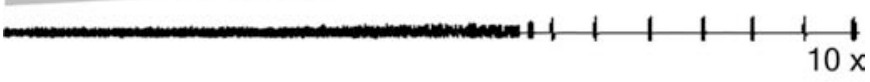

\section{(c) Superficial Pyramidal Cell Activity}

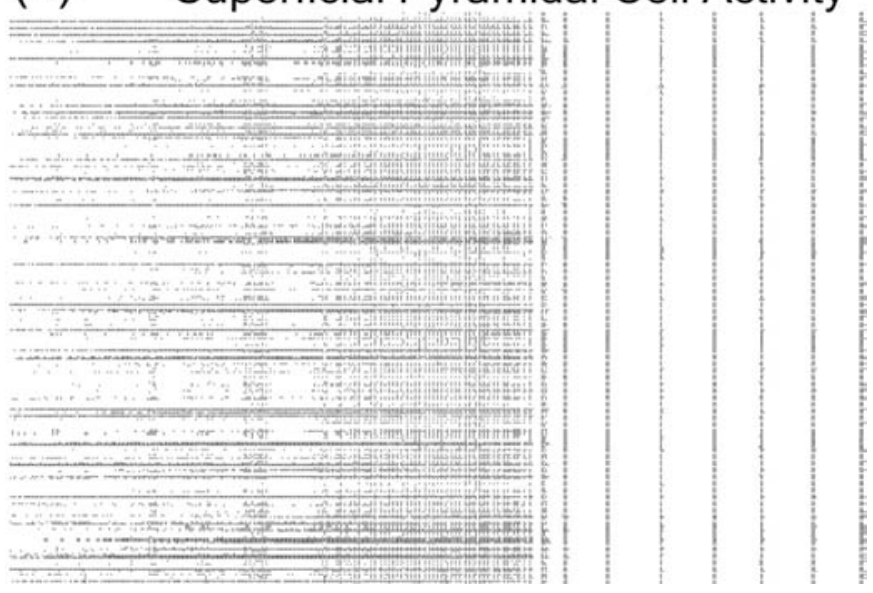

Fig. 3. Simulated network dynamics during decreasing strength of excitatory synaptic transmission. (a) Multi-unit activity in a network without bursting neurons. (b) Extracellular activity from a network including spontaneously bursting cells. (c) Rasterplots of activity in the superficial pyramidal neurons associated with example (b). As shown with the grey indicators, the strength of the excitatory synapses was reduced over the first part of each simulation, following the trajectory indicated by 'Path to Seizure Onset' in Fig. 2. In each example, the simulated extracellular signal generated by the excitatory neuronal population is shown in the top trace and the extracellular signal from the inhibitory population is shown at a 10x larger scale in the bottom traces. Lower excitatory coupling (at values around 0.5) causes network oscillations. The network without bursting cells becomes inactive at excitatory strengths below 0.2 (a), whereas activity is sustained when bursting neurons are present (b). The rasterplots show that pyramidal cells become recruited at the onset of the seizure-like oscillatory pattern and demonstrate hypersynchronous activity later during the regular bursting. Interestingly this is also the only pattern in which the inhibitory cell population shows bursting.

Generally speaking, the network behavior could be classified as inactive, desynchronized (D), oscillatory (O), irregular (IB) and regular bursting (RB), (Fig. 2). Regular bursting and oscillatory behavior resembled recorded epileptiform activity and were only observed in weakly connected networks. In contrast, higher levels of excitatory connectivity resulted in desynchronized activity or irregular bursting. In networks without spontaneously bursting neurons, the RB activity was never observed; instead the network became inactive at low (a)
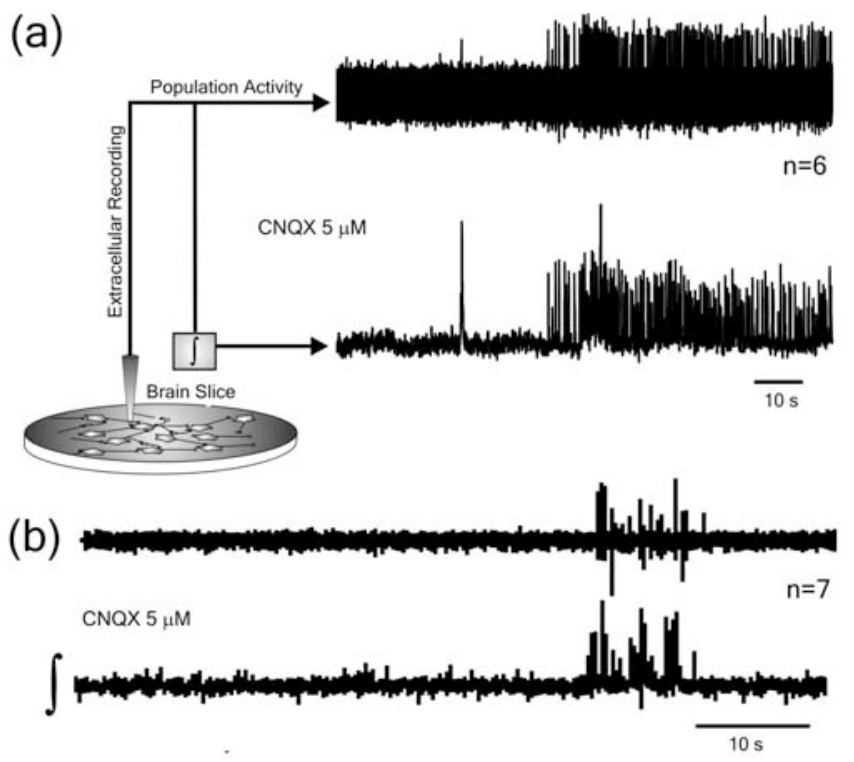

(c)

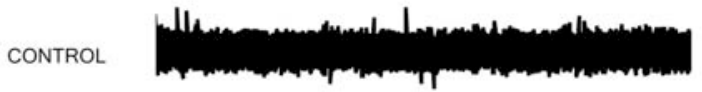

$\mathrm{CNQ} \times 6 \mu \mathrm{M}$

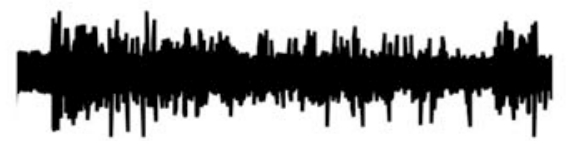

$\mathrm{CNQX} 15 \mu \mathrm{M}$

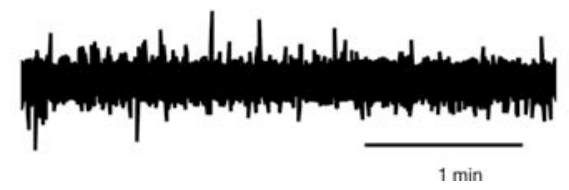

Fig. 4. Results from recorded seizure-like activity in neocortical slices of adult mouse under the influence of CNQX $(n=15)$. (a) Recorded extracellular multi-unit activity (upper trace) and the corresponding rectified and integrated $\left(\int\right.$ ) signal (lower trace). Bursting pattern $>10 \mathrm{~s}$ were recorded in 6 cases (a) and shorter bursts (2-10 s) in 7 cases. (b). The extracellular recordings in (c) demonstrate that seizure-like bursts occurred at $6 \mu \mathrm{M}$ CNQX, whereas lower and higher concentrations displayed lower level and desynchronized activity.

levels of excitatory transmission [16]. Behavior similar to recordings of seizure onsets was obtained when the synaptic excitation strength was dynamically reduced from a high initial value (Fig. 3a, b). In these plots, the contributions of the excitatory and inhibitory populations are shown separately. Overall the contribution of the inhibitory neurons is more than an order of magnitude smaller than the excitatory population's activity. Highly synchronized bursting occurred at strengths $\leq 0.2$ in networks that included spontaneously bursting neurons. Interestingly, this highly synchronous state is also associated with bursting in the inhibitory cell type (bottom trace in Fig. 3b). Raster plots of superficial pyramidal cell activity (Fig. 3c) showed that the pattern changed from desynchronized activity at synaptic excitation strengths around 3 to modestly synchronized at the onset of the seizurelike discharge at $\sim 0.5$.

\section{EXPERIMENTAL DATA}


We have recorded network activity extracellularly in mouse neocortical slices while pharmacologically reducing synaptic coupling strength. Initially, we mimicked a low $\mathrm{Ca}^{++}$scenario known to be associated with propagating neocortical seizures in the baboon [31]; low concentrations $(20$ to $60 \mu \mathrm{M})$ of $\mathrm{Cd}^{++}$ were added to the artificial cerebrospinal fluid (ACSF) surrounding the slice to block $\mathrm{Ca}^{++}$-mediated processes. Repetitive network bursting resulted in 5 out of 5 cases. But because the weakening of synaptic connection is only one of the many effects of $\mathrm{Cd}^{++}$, we performed a more targeted experiment in which CNQX was used to reduce the synaptic strength of the non-NMDA mediated excitatory glutamate receptors. Moderate concentrations of CNQX $(4-12 \mu \mathrm{M})$ applied to neocortical slices from older mice $(>\mathrm{P} 18)$ induced repetitive bursting in 13 out of 15 cases. Six of these cases included periods of seizure-like bursting that persisted for $10-120 \mathrm{~s}$ and included $>25$ bursts (Fig. 4a). The other 7 cases displayed 2-10 s intervals containing 6-15 network bursts at frequencies between $1 \mathrm{~Hz}$ and $3 \mathrm{~Hz}$ (Fig. 4b). In all slices, high concentrations of CNQX $(>15 \mu \mathrm{M})$ stopped network bursting completely (Fig. 4c).

\section{DISCUSSION}

The results obtained from this computational model indicate that neural networks can generate and sustain seizure-like activity if the excitatory coupling strength falls below a critical value. These results contradict the common belief that strong excitatory coupling is needed to synchronize bursting. In our simulations, increasing the strength of excitatory connectivity actually destroys the ability of the synchronously firing spontaneously active neurons to dominate network behavior (Fig. 2).

Our neocortical slice experiments show that weakening excitatory transmission using CNQX at moderate concentrations between $4 \mu \mathrm{M}$ and $12 \mu \mathrm{M}$ can evoke seizurelike activity. This finding agrees well with the prediction from our modeling that weakening excitatory coupling strength allows epileptiform network oscillations to occur (Figs. 2 and $3)$. However we cannot exclude the possibility that our observations relate specifically to NMDA-mediated signals because CNQX attenuates the non-NMDA-mediated synaptic transmission. NMDA could play such a role as [32] observed that the frequency of slow oscillations increase after blocking NMDA. However, our finding that high levels of CNQX (> $15 \mu \mathrm{M})$ stopped all network oscillations suggests that some of the AMPA mediated transmission must be intact for the generation of the bursting we observed.

The activity pattern in Fig. 3c confirms a recent experimental finding that the level of synchrony at seizure onset may in fact be modest as compared to a further developed seizure state [13]-[15]. Intra-operative recordings during seizures in patients with epilepsy indicate that this finding is relevant for true seizure activity (see e.g., [33]).

Our hypothesis linking reduced excitation with seizure activity, appears to be contradicted by several well-known results. For instance, the direct measurements of evoked excitatory postsynaptic potentials (EPSPs) by [34] show a slight increase of amplitude and decrease of latency around seizure onset. But we note that the evoked EPSPs may not represent the overall state of all synaptic transmission involved, and the real parameter to establish would be synaptic drive defined as the product of the synaptic firing rate and postsynaptic current amplitude [35].

Another example is bicuculline, a $\mathrm{GABA}_{\mathrm{A}}$ receptor antagonist, that is routinely applied to evoke epileptiform activity in cortical slices. This activity pattern is sometimes seizure-like [36], but more often the evoked activity consists of isolated bursts or bursting patterns at low frequencies (typically $<0.1 \mathrm{~Hz}$ ) that are considered representative of interictal spikes. We found that bicuculline $(20 \mu \mathrm{M})$ applied to mouse neocortical slices from neonates (P8-P13) also evoked a series of seizure-like, transient bursts at frequencies $>1 \mathrm{~Hz}(n=15)$ [14]. Reference [12] described a similar observation for young rat, in which bicuculline evoked seizure-like bursting in neocortical slices from animals younger than P15. These observations may relate to the different role of the $\mathrm{GABA}_{\mathrm{A}}$ receptor before and after $\mathrm{P} 15$ in mouse and rat: because of developmental differences in the intracellular $\left[\mathrm{Cl}^{-}\right]$, the $\mathrm{GABA}_{\mathrm{A}}$ receptor has a depolarizing (excitatory) effect in juveniles younger than P15 and a hyperpolarizing (inhibitory) effect in older neocortex [37], [38]. Considering the excitatory role of $\mathrm{GABA}_{\mathrm{A}}$ in juveniles, the bicuculline evoked seizure-like bursting in this age group is consistent with our hypothesis that reduced excitatory coupling causes seizures to occur.

In light of the computational results and the electrophysiological evidence reported here, it appears that the commonly held view that seizures are necessarily characterized by hypersynchrony and hyperexcitation should be re-examined. We also emphasize that, considering the variability and complexity of epileptic seizure activity, it is likely that seizure onset is a final common path for a variety of mechanisms starting from a different initial state of brain activity. Nonetheless, our results show that a computational model can now mimic seizure onset in enough detail to directly test the consequences of alterations in cellular and network parameters against experimental observations. A better understanding of the interplay of these factors will ultimately lead to a more theoretically rigorous methodology for the treatment of epilepsy.

\section{ACKNOWLEDGMENT}

The authors appreciated useful discussions with Drs. Charles Marcuccilli, Michael Carroll, Kurt Hecox, and Jan-Marino Ramirez.

\section{REFERENCES}

[1] P. Kwan and M. J. Brodie, "Early identification of refractory epilepsy," N. Engl. J. Med. vol. 342, pp. 314-319, 2000.

[2] J. Gotman, "Automatic seizure detection: improvements and evaluation,”. Electroenceph. clin. Neurophysiol. vol. 76, pp. 317-324, 1990.

[3] A. V. Delgado-Escueta, W. A. Wilson, R. W. Olsen, and R. J. Porter, "New waves of research in the epilepsies: Crossing into the third millennium," in Advances in Neurology vol. 79: Jasper's Basic Mechanisms of Epilepsies, A.V. Delgado-Escueta, W.A. Wilson, R.W. 
Olsen, and R.J. Porter, eds. Philadelphia: Lippincot, Williams \& Wilkins, 1999, pp. 3-58.

[4] B. W. Connors, "Initiation of synchronized neuronal bursting in neocortex," Nature vol. 310, pp. 685-687, 1984.

[5] B. W. Connors and Y. Amitai, "Generation of epileptiform discharge by local circuits of neocortex," in Epilepsy, P.A. Schwartzkroin, ed. New York: Cambridge University Press, 1993, pp. 388-423.

[6] F. E. Dudek, J. P. Wuarin, J. G. Tasker, Y. I. Kim, and W. J. Peacock, "Neurophysiology of neocortical slices resected from children undergoing surgical treatment for epilepsy," J. Neurosci. Methods vol. 59, pp. 49-58, 1995.

[7] M. J. Gutnick, B. W. Connors, and D. A. Prince, "Mechanisms of neocortical epileptogenesis in vitro," J. Neurophysiol. vol. 48, pp. 1321$1335,1982$.

[8] J. G. Tasker, N. W. Hoffman, Y. I. Kim, R. S. Fisher, W. J. Peacock, and F. E. Dudek, "Electrical properties of neocortical neurons in slices from children with intractable epilepsy," J Neurophysiol. vol. 75, pp. 931939, 1996.

[9] R. D. Traub, J. G. Jefferys, R. Miles, M. A. Whittington, and K. Toth, "A branching dendritic model of a rodent CA3 pyramidal neurone," $J$. Physiol. vol. 481, pp. 79-95, 1994.

[10] R. D. Traub and R. Llinas, "Hippocampal pyramidal cells: Significance of dendritic ionic conductances for neuronal function and epileptogenesis," J Neurophysiol. vol. 42, pp. 476-496, 1979.

[11] J. P. Wuarin, Y. I. Kim, C. Cepeda, J. G. Tasker, J. P. Walsh, W. J. Peacock, N. A. Buchwald, and F. E. Dudek, "Synaptic transmission in human neocortex removed for treatment of intractable epilepsy in children," Ann. Neurol. vol. 28, 503-511, 1990.

[12] Khazipov, R., Khalilov, I., Tyzio, R., Morozova, E., Ben Ari, Y., and Holmes, G.L. (2004). Developmental changes in GABAergic actions and seizure susceptibility in the rat hippocampus. Eur. J. Neurosci. 19, $590-600$.

[13] T. I. Netoff and S. J. Schiff, "Decreased neural synchronization during experimental seizures," J. Neurosci. vol. 22, pp. 7297-7307, 2002.

[14] W. van Drongelen, H. Koch, C. Marcuccilli, F. Peña, and J-M Ramirez, "Synchrony levels during evoked seizure-like bursts in mouse neocortical slices," J. Neurophysiol. vol. 90, 1571-1580, 2003.

[15] M. Steriade and D. Contreras, "Relations between cortical and thalamic cellular events during transition from sleep patterns to paroxysmal activity," J. Neurosci. vol. 15, pp. 623-642, 1995.

[16] W van Drongelen, H. C. Lee, M. Hereld, D. Jones, M. Cohoon, F. Elsen, M. E. Papka, and R. L. Stevens, "Simulation of neocortical epileptiform activity using parallel computing," Neurocomputing vol. 58-60, pp. 1203-1209, 2004.

[17] W van Drongelen W, H. C. Lee, H. Koch, F. Elsen, M. S. Carroll, M. Hereld, and R. L. Stevens, "Interaction between cellular voltagesensitive conductance and network parameters in a model of neocortex can generate epileptiform bursting," IEEE Catalog No: 04CH37558C, ISBN: 0-7803-8440-7: pp. 4003-4005a, 2004.

[18] J. M. Bower and D. Beeman, The book of GENESIS. New York: Springer, 1998.

[19] P. L. Nunez, Electric fields of the brain: The neurophysics of EEG. Oxford: Oxford University Press, 1981.

[20] A. L. Hodgkin and A. F. Huxley, "A quantitative description of membrane current and its application to conduction and excitation in nerve," J. Physiol. vol. 117, pp. 500-544, 1952.

[21] A. Destexhe and D. Pare, "Impact of network activity on the integrative properties of neocortical pyramidal neurons in vivo," J. Neurophysiol. vol. 81, 1531-1547, 1999.

[22] D. Golomb and Y. Amitai, "Propagating neuronal discharges in neocortical slices: computational and experimental study," J. Neurophysiol. vol. 78, pp. 1199-1211, 1997.

[23] R. J. Butera, J. Rinzel, and J. C. Smith, "Models of repiratory rhythm generation in the pre-Bötzinger complex, I: Bursting pacemaker neurons," J. Neurophysiol. vol. 82, pp. 382-397, 1999.

[24] J. DeFelipe, L. Alonso-Nanclares, and J. I. Arellano, (2002). "Microstructure of the neocortex: Comparative aspects," J. Neurocytol. vol. 31, pp. 299-316, 2002.
[25] V. B. Mountcastle, "The columnar organization of the neocortex," Brain vol. 120, pp. 701-722, 1997.

[26] R. Nieuwenhuys, "The neocortex: An overview of its evolutionary development, structural organization and synaptology," Anat. Embryol. 190, pp. 307-337, 1994.

[27] R. J. Douglas and K. A. C. Martin, "Neocortex," in: The synaptic organization of the brain, G.M. Shepherd, ed. Oxford: Oxford University Press, 1990, pp. 389-438.

[28] L. S. Krimer and P. S. Goldman-Rakic, "Prefrontal microcircuits: Membrane properties and excitatory input of local, medium and wide arbor interneurons," J. Neurosci. vol. 21, pp. 3788-3796, 2001.

[29] Y. Wang, A. Gupta, M. Toledo-Rodriguez, C. Z. Wu, and H. Markram, "Anatomical, physiological, molecular and circuit properties of nest basket cells in the developing somatosensory cortex," Cerebral Cortex vol. 12, pp. 395-410, 2002.

[30] R. D. Traub and R. Miles, Neuronal networks of the hippocampus. New York: Cambridge University Press, 1991.

[31] R. Pumain, C. Menini, U. Heinemann, J. Louvel, and C. Silva-Barrat, "Chemical synaptic transmission is not necessary for epileptic seizures to persist in the baboon Papio papio," Exp. Neurol. vol. 89, pp. 250258, 1985.

[32] M. Steriade, A. Nuñez, and F. Amzica, "A novel slow $(<1 \mathrm{~Hz})$ oscillation of neocortical neurons in vivo: depolarizing and hyper polarizing components," J Neurosci. vol. 13, pp. 3252-3265, 1993.

[33] A. R. Wyler, G. A. Ojemann, and A. A. Ward, "Neurons in human epileptic cortex: Correlation between unit and EEG activity," Ann. Neurol. vol.11, pp. 301-308, 1982.

[34] M. Steriade and F. Amzica, "Intracellular study of excitability in the seizure-prone neocortex in vivo," J. Neurophysiol. vol. 82, pp. 3108$3122,1999$.

[35] S. B. Nelson and G. G. Turrigiano, "Synaptic depression: A key player in the cortical balancing act," Nature Neurosci. 1, pp. 539-541, 1998.

[36] M. Steriade, F. Amzica, D. Neckelmann, and I. Timofeev, "Spike-wave complexes and fast components of cortically generated seizures. II. Extra- and intracellular patterns," $J$ Neurophysiol. vol. 80, pp. 14561479, 1998.

[37] P. Benitez-Diaz, L. Miranda-Contreras, R. V. Mendoza-Brineco, Z. Pena-Contreras, and E. Palacios-Pru, "Prenatal and postnatal contents of amino acid neurotransmitters in mouse parietal cortex," Dev. Neurosci. vol. 25, pp. 366-374, 2003.

[38] D. F. Owens, L. H. Boyce, M. B. E. Davis, and A. R. Kriegstein, "Excitatory GABA responses in embryonic and neonatal cortical slices demonstrated by gramicidin perforated-patch recordings and calcium imaging," J. Neurosci. vol. 16, pp. 6414-6423, 1996.

The submitted manuscript has been created by the University of Chicago as Operator of Argonne National Laboratory ("Argonne") under Contract No. W-31-109-ENG-38 with the U.S. Department of Energy. The U.S. Government retains for itself, and others acting on its behalf, a paid-up, nonexclusive, irrevocable worldwide license in said article to reproduce, prepare derivative works, distribute copies to the public, and perform publicly and display publicly, by or on behalf of the Government. 
